\title{
Effects of hemodynamic alterations on anterior mitral leaflet curvature during systole
}

Hiroaki Sakamoto, MD, ${ }^{*}$ Landi M. Parish, SB, ${ }^{*}$ Hirotsugu Hamamoto, MD, Yoshiharu Enomoto, MD, Ahmad Zeeshan, MD, Theodore Plappert, CVT, Benjamin M. Jackson, MD, Martin G. St. John-Sutton, MD, Robert C. Gorman, MD, and Joseph H. Gorman III, MD

From the Harrison Department of Surgical Research, Department Surgery, School of Medicine, University of Pennsylvania, Philadelphia, Pa.

Funded by the National Heart, Lung, and Blood Institute, National Institutes of Health, Bethesda, Md (HL63954, HL71137, HL73021); and the Mary L. Smith Charitable Trust and W.W. Smith Charitable Trust, Newtown Square, Pa.

Received for publication April 12, 2006; accepted for publication Aug 25, 2006.

Address for reprints: Joseph H. Gorman, III, MD, University of Pennsylvania, 313 Stemmler Hall, 36th and Hamilton Walk, Philadelphia, PA 19104 (E-mail: gormanj@ uphs.upenn.edu).

*Both authors contributed equally.

J Thorac Cardiovasc Surg 2006;132:1414-9

$0022-5223 / \$ 32.00$

Copyright (C) 2006 by The American Association for Thoracic Surgery

doi:10.1016/j.jtcvs.2006.08.036
Objectives: The application of repair techniques to treat mitral valve incompetence has increased progressively during the past 20 years. Unfortunately, recent reports have demonstrated the longevity of these repairs to be less than previously believed. Most repair failures are stress related. Computational models to optimize valve repair are in development, but to be brought to fruition, a better understanding of dynamic leaflet geometry is necessary. In this study, sonomicrometry was used in an ovine model to compute systolic leaflet curvature at varying afterloads and states of contractility.

Methods: The anterior leaflet of 12 sheep was instrumented with 5 piezoelectric transducers in a cruciate array. Systolic blood pressure ranged from 90 to $200 \mathrm{~mm}$ $\mathrm{Hg}$ with increasing phenylephrine hydrochloride infusion. Epinephrine was used to vary contractile state. Leaflet curvature was calculated continuously $(200 \mathrm{~Hz})$ during systole.

Results: Anterior leaflet curvature in the septolateral direction was double that in the intercommisural direction. There were also significant changes in leaflet curvature during systole. Curvature in neither direction was affected by afterload. Epinephrine augmented intercommisural curvature in a dose-independent fashion, whereas it had no effect on curvature in the septolateral direction.

Conclusions: Dynamic mitral anterior leaflet geometry was found to be amazingly constant over a wide range of hemodynamic conditions. These data provide information about leaflet geometry that will aid in the construction of realistic computational models. Such models may facilitate the design of annuloplasty rings and surgical techniques that minimize leaflet stress and increase mitral valve repair longevity.

$\mathrm{T}$ he development and application of standardized techniques have produced a progressive increase in both the number of mitral valve repair procedures being performed and the number of surgeons performing them worldwide.

Unfortunately, recent long-term studies using more rigorous definitions of failure have identified mitral valve repair durability to be much less robust than previously described. ${ }^{1-4}$ In most cases, failures reported in these studies were a result of disruption at the leaflet, chordal, or annular suture lines, suggesting excessive tissue stress as an etiologic factor. These results indicate that repair techniques can be improved.

To this end, there has been increased interest in understanding how leaflet geometry, in particular, leaflet curvature, affects leaflet stress distribution. ${ }^{5-8} \mathrm{Al}-$ though thought provoking and potentially helpful in designing new repair techniques, this theoretic work has been hindered by a lack of quantitative in vivo data describing the effect of hemodynamic conditions on leaflet curvature. We present for the first time a quantitative assessment of the effect of both afterload and contractility on leaflet surface curvature in 2 orthogonal directions. 


$$
\begin{aligned}
& \text { Abbreviations and Acronyms } \\
& \begin{aligned}
\mathrm{ARP} & =\text { aortic root pressure } \\
\mathrm{ED} & =\text { end diastole } \\
\mathrm{ES} & =\text { end systole } \\
\mathrm{MS} & =\text { mid-systole }
\end{aligned}
\end{aligned}
$$

\section{Materials and Methods \\ Surgical Protocol}

In compliance with the "Guide for the Care and Use of Laboratory Animals," 12 male Dorsett sheep (35-45 kg) were induced with sodium thiopental (10-15 mg/kg intravenously), intubated, anesthetized, and ventilated with isofluorane (1.5\%-2.0\%) and oxygen. The surface electrocardiogram and blood pressure were continuously monitored.

Through a sterile left lateral thoracotomy, five 1-mm hemispherical piezoelectric transducers (Sonometrics Corp, London, Ontario) were implanted on the anterior leaflet of each sheep during cardiopulmonary bypass. The transducers were placed in an equally spaced $15 \times 15-\mathrm{mm}$ cruciate pattern (Figure 1 ). Three crystals $(\mathrm{C} 1, \mathrm{C} 2$, and $\mathrm{C} 3)$ were equally placed on the intercomisural line. $\mathrm{C} 1$ and $\mathrm{C} 3$ were placed approximately $3 \mathrm{~mm}$ from the anterior and posterior commissures, respectively. $\mathrm{C} 2$ was placed as near the center of the leaflet as possible. Two additional crystals (C4 and C5) were placed to form a septolateral line that included the center crystal of the intercomissural line (C2). C4 was placed near the saddle horn of the annulus approximately $3 \mathrm{~mm}$ from the annulus. C5 was placed $3 \mathrm{~mm}$ from the edge of the leaflet. One 1-mm transducer on the middle portion of the posterior mitral annulus and two 2-mm transducers on the left atrium were placed for orientation. An aortic flow probe was implanted to measure cardiac output. After each sheep was weaned from cardiopulmonary bypass and hemodynamically stable, an epicardial echocardiogram was performed to assess valve competence. The chest was closed with the sonomicrometer skin buttons fixed to the skin, and the animal recovered.

\section{Data Acquisition}

One week after instrumentation, the sheep were again sedated with thiopental, placed supine, intubated, anesthetized with isofluorane, and mechanically ventilated. A high-fidelity double-pressure transducer (SPC-350, Millar Instruments Inc, Houston, Tex) for simultaneous measurements of left ventricular and aortic root pressures (ARPs) was passed percutaneously into the left ventricle through a femoral artery. A pulmonary artery catheter (7F; Baxter Healthcare Corp, Deerfield, Ill) was also placed. Surface electrocardiogram, left ventricular pressure, ARPs, left ventricular end-diastolic pressure, central venous pressure, and cardiac output were monitored continuously (Hewlett-Packard 78534C monitor). Transducer wires were connected to a Sonometrics Series 5001 Digital Sonomicrometer (Sonometrics Corp).

To study the effect of afterload and contractility on anterior leaflet curvature, hemodynamic and sonomicrometry data were collected in each of the following conditions: (1) inhaled isofluorane was titrated to a baseline systolic ARP of $90 \mathrm{~mm} \mathrm{Hg}$ (LN condition); (2) a phenylephrine hydrochloride infusion was then titrated to achieve systolic blood pressures of $150 \mathrm{~mm} \mathrm{Hg}(\mathrm{MN}$ condition) and $200 \mathrm{~mm} \mathrm{Hg}$ (HN condition); (3) phenylephrine hydrochloride was discontinued, and the sheep were allowed to return to a baseline ARP of $90 \mathrm{~mm} \mathrm{Hg}$; (4) epinephrine was dosed at 2 $\mu \mathrm{g} / \mathrm{min}$ (LE condition), $5 \mu \mathrm{g} / \mathrm{min}$ (ME condition), and $10 \mu \mathrm{g} / \mathrm{min}$
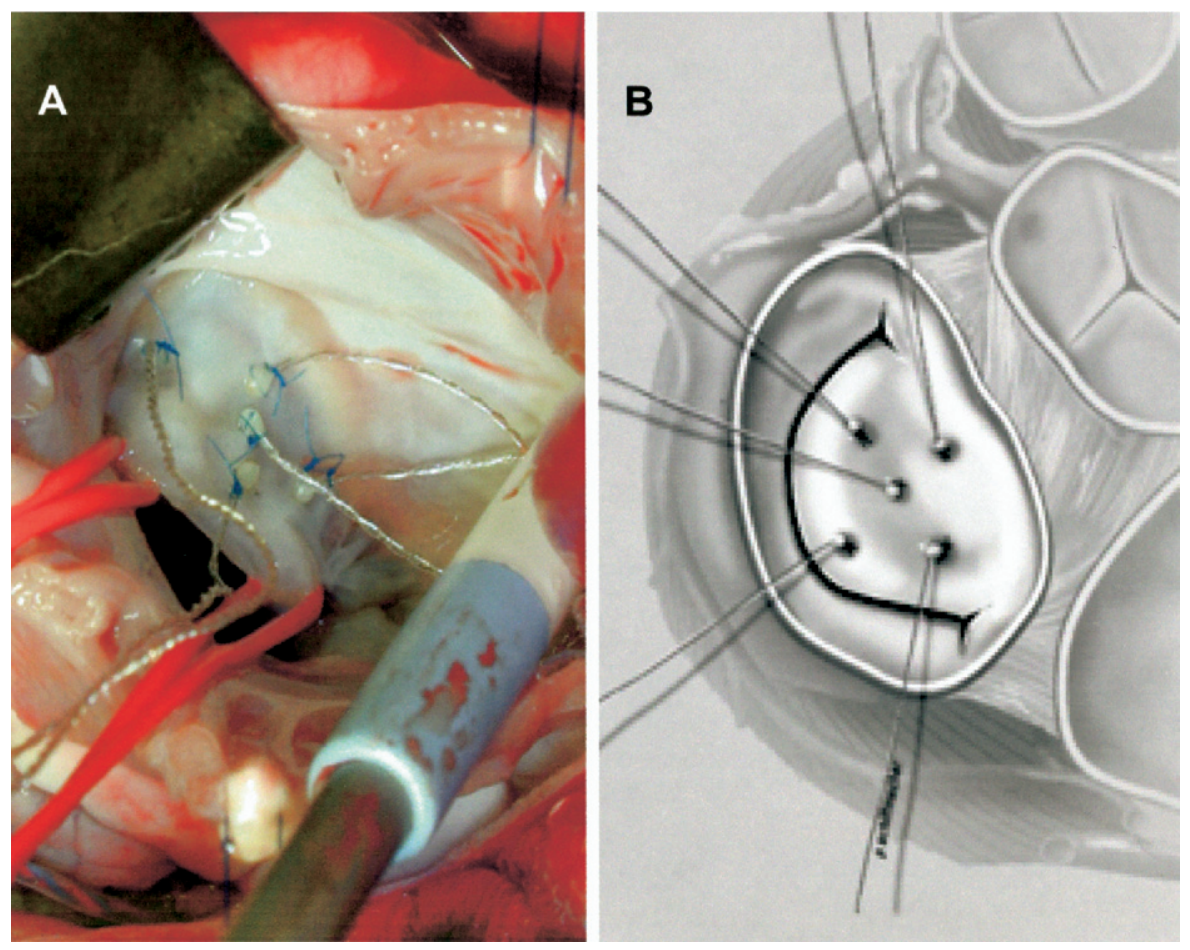

Figure 1. A, Intraoperative photograph of the anterior leaflet of the mitral valve demonstrating the location of the 1-mm sonomicrometry crystals on a representative sheep. $B$, Schematic more clearly illustrating the array used to measure anterior leaflet curvature in 2 orthogonal directions: septolateral and intercommisural. 
TABLE 1. Hemodynamic data for afterload conditions

\begin{tabular}{lccc}
\hline Afterload & Low & Medium & High \\
\hline HR (beats/min) & $114 \pm 6$ & $103 \pm 5$ & $106 \pm 4$ \\
ARP (mm Hg) & & & \\
$\quad$ Systolic* $† \ddagger$ & $90 \pm 0$ & $152 \pm 1$ & $199 \pm 1$ \\
$\quad$ Diastolic* $† \ddagger$ & $53 \pm 3$ & $106 \pm 6$ & $133 \pm 6$ \\
LVEDP (mm Hg)* & $2 \pm 2$ & $7 \pm 2$ & $11 \pm 2$ \\
CVP (mm Hg) $† \ddagger$ & $9 \pm 1$ & $9 \pm 1$ & $11 \pm 2$ \\
PAP (mm Hg) & & & \\
Systolic* & $25 \pm 2$ & $34 \pm 2$ & $48 \pm 3$ \\
$\quad$ Diastolic* & $16 \pm 2$ & $21 \pm 1$ & $28 \pm 2$ \\
CO (L/min) & $2.9 \pm 0.2$ & $3.0 \pm 0.2$ & $3.4 \pm 0.3$
\end{tabular}

Hemodynamic data for afterload conditions. $H R$, Heart rate; $A R P$, aortic root pressure; $L V E D P$, left ventricular end-diastolic pressure; CVP, central venous pressure; $P A P$, pulmonary artery pressure; $C O$, cardiac output. $* P<.05$ between low and medium conditions. $\dagger P<.05$ between low and high afterload conditions. $\$ P<.05$ between medium and high afterload conditions.

(HE condition). Transdiaphragmatic echocardiograms were performed, as previously described, ${ }^{9}$ at each hemodynamic condition to document valve competence. Between each hemodynamic manipulation, the animals were allowed to stabilize for 15 minutes before sonomicrometry data were recorded. Ventilation was suspended during sonomicrometry measurements.

At the completion of these experiments, animals were euthanized with $1 \mathrm{~g}$ of thiopental and $80 \mathrm{mEq}$ of $\mathrm{KCl}$. Hearts were removed and opened to verify the placement of the sonomicrometry transducers.

\section{Data Analysis}

As described previously, sonomicrometry array localization was used to determine the 3-dimensional coordinates of each transducer every $5 \mathrm{~ms}$ during systole. End diastole (ED) and end systole (ES) were determined as previously described. ${ }^{10}$ Mid systole (MS) is defined as the point halfway between ED and ES. To facilitate comparison, all datasets were normalized in time by means of linear interpolation (Matlab, The MathWorks, Natick, Mass). ${ }^{11}$

Curvature $(\mathrm{K})$ was calculated as the inverse of the radius of curvature, as follows. Let a, b, and c be the distances between each of the 3 crystals $(\mathrm{C} 1, \mathrm{C} 2$, and $\mathrm{C} 3$ for intercommisural curvature and $\mathrm{C} 4, \mathrm{C} 2$, and $\mathrm{C} 5$ for septolateral curvature). Then curvature is given by

$$
K=\frac{\sqrt{(a+b+c) \cdot(b+c-a) \cdot(c+a-b) \cdot(a+b-c)}}{a \cdot b \cdot c}
$$

Each curvature was averaged within each condition at each time point for all sheep to form composite measures and plotted against time. Positive curvature is concave toward the ventricle. Multivariate analysis of variance (Statistical Package for the Social Sciences, SPSS Inc, Chicago, Ill) was used to assess the affect of direction on the leaflet, time during systole, and hemodynamic conditions on the degree of curvature. Hemodynamic data were compared in parallel with sonomicrometry array localization data by using the same statistical methods. Data are presented as mean \pm standard error of the mean. The funding sources had no role in interpreting the data.
TABLE 2. Hemodynamic data for contractility conditions

\begin{tabular}{|c|c|c|c|}
\hline Contractility & Low & Medium & High \\
\hline HR (beats/min)†‡ & $124 \pm 7$ & $126 \pm 6$ & $135 \pm 6$ \\
\hline \multicolumn{4}{|l|}{ ARP $(\mathrm{mm} \mathrm{Hg})$} \\
\hline Systolict‡ & $106 \pm 5$ & $111 \pm 5$ & $124 \pm 5$ \\
\hline Diastolic & $65 \pm 7$ & $70 \pm 8$ & $77 \pm 9$ \\
\hline LVEDP (mm Hg) & $2 \pm 2$ & $2 \pm 2$ & $2 \pm 2$ \\
\hline CVP $(\mathrm{mm} \mathrm{Hg})$ & $8 \pm 1$ & $9 \pm 1$ & $9 \pm 1$ \\
\hline \multicolumn{4}{|l|}{ PAP $(\mathrm{mm} \mathrm{Hg})$} \\
\hline Systolic & $27 \pm 1$ & $28 \pm 2$ & $30 \pm 3$ \\
\hline Diastolic & $18 \pm 1$ & $18 \pm 1$ & $19 \pm 2$ \\
\hline $\mathrm{CO}(\mathrm{L} / \mathrm{min})^{*} \dagger \ddagger$ & $4.0 \pm 0.2$ & $4.8 \pm 0.4$ & $5.6 \pm 0.4$ \\
\hline
\end{tabular}

Hemodynamic data for epinephrine conditions. $H R$, Heart rate; $A R P$, aortic root pressure; $L V E D P$, left ventricular end-diastolic pressure; $C V P$, central venous pressure; $P A P$, pulmonary artery pressure; $C O$, cardiac output. $* P<.05$ between low and medium contractility conditions. $\dagger P<.05$ between low and high contractility conditions. $\ddagger P<.05$ between medium and high contractility conditions.

\section{Results}

\section{Hemodynamics}

The hemodynamics for both the afterload and contractility studies are presented in Tables 1 and 2, respectively. Both systolic and diastolic ARP differed significantly $(P<.05)$ between all afterload conditions. Heart rate did not vary significantly across afterload conditions.

Systolic ARP differed significantly between the LE and $\mathrm{HE}$ conditions and the ME and HE conditions. The difference in heart rate was significant between $\mathrm{HE}$ and both $\mathrm{ME}$ and LE conditions $(P<.05)$. Cardiac output was $4.0 \pm 0.2$ $\mathrm{L} / \mathrm{min}, 4.8 \pm 0.4 \mathrm{~L} / \mathrm{min}$, and $5.6 \pm 0.4 \mathrm{~L} / \mathrm{min}$ in the $\mathrm{LE}$, $\mathrm{ME}$, and $\mathrm{HE}$ conditions, respectively. All differences in cardiac output were significant.

TABLE 3. Change in curvature with afterload

\begin{tabular}{llll}
\hline Afterload & \multicolumn{1}{c}{ Low } & \multicolumn{1}{c}{ Medium } & \multicolumn{1}{c}{ High } \\
\hline $\mathrm{K}_{\mathrm{IC}}(1 / \mathrm{m})$ & & & \\
ED & $58.5 \pm 10.0$ & $52.3 \pm 10.4$ & $68.3 \pm 11.4$ \\
$\mathrm{MS}$ & $53.7 \pm 7.6$ & $51.5 \pm 7.6$ & $63.6 \pm 8.6$ \\
$\mathrm{ES}$ & $64.7 \pm 9.4$ & $59.3 \pm 8.8$ & $70.5 \pm 10.0$ \\
$\mathrm{~K}_{\mathrm{SL}}(1 / \mathrm{m})$ & & & \\
ED & $134.2 \pm 20.1^{*} \dagger$ & $124.9 \pm 21.5^{*} \dagger$ & $150.0 \pm 24.7^{*} \dagger$ \\
$\mathrm{MS}$ & $122.5 \pm 18.7$ & $111.2 \pm 19.5$ & $133.3 \pm 24.1$ \\
$\mathrm{ES}$ & $124.0 \pm 19.7$ & $112.8 \pm 19.5$ & $131.4 \pm 25.3$ \\
\hline
\end{tabular}

Intercommisural curvature $\left(\mathrm{K}_{\mathrm{IC}}\right)$ and septolateral curvature $\left(\mathrm{K}_{\mathrm{SL}}\right)$ at $\mathrm{ED}, \mathrm{MS}$, and ES under 3 conditions: low, medium, and high afterload. The difference between intercommisural and septolateral curvature was significant at every time point in every condition. There was no significant change in either curvature between afterload conditions at ED, MS, or ES. *Significant difference between ED and MS within each afterload condition. $\dagger$ Significant difference between ED and ES within each afterload condition. $\mathrm{K}_{\mathrm{IC}}$ did not vary at all through the cardiac cycle at any afterload condition. 
TABLE 4. Change in curvature with contractility

\begin{tabular}{llll}
\hline Contractility & \multicolumn{1}{c}{ Low } & \multicolumn{1}{c}{ Medium } & \multicolumn{1}{c}{ High } \\
\hline $\mathrm{K}_{\mathrm{IC}}(1 / \mathrm{m})$ & & & \\
$\mathrm{ED}$ & $66.2 \pm 12.1 \dagger$ & $64.7 \pm 12.2 \dagger$ & $59.6 \pm 11.7 \dagger$ \\
$\mathrm{MS}$ & $66.7 \pm 7.4 \ddagger$ & $63.4 \pm 11.8 \ddagger$ & $63.2 \pm 8.6 \ddagger$ \\
$\mathrm{ES}$ & $82.6 \pm 9.3$ & $77.2 \pm 13.4$ & $75.7 \pm 12.0$ \\
$\mathrm{~K}_{\mathrm{SL}}(1 / \mathrm{m})$ & & & \\
ED & $157.1 \pm 23.1^{*} \dagger$ & $148.3 \pm 24.4^{*} \dagger$ & $148.5 \pm 23.9^{*} \dagger$ \\
$\mathrm{MS}$ & $137.5 \pm 24.6$ & $128.5 \pm 25.6$ & $130.5 \pm 25.9$ \\
$\mathrm{ES}$ & $140.3 \pm 24.3$ & $132.8 \pm 25.0$ & $133.1 \pm 26.2$ \\
\hline
\end{tabular}

Intercommisural curvature $\left(\mathrm{K}_{\mathrm{IC}}\right)$ and septolateral curvature $\left(\mathrm{K}_{\mathrm{SL}}\right)$ at $\mathrm{ED}, \mathrm{MS}$, and ES under 3 conditions: $2 \mu \mathrm{g} / \mathrm{min}$ (low), $5 \mu \mathrm{g} / \mathrm{min}$ (medium), and 10 $\mu \mathrm{g} / \mathrm{min}$ (high) epinephrine. The difference between intercommisural and septolateral curvature was significant at every time point during every condition. As in the afterload study, $\mathrm{K}_{\mathrm{SL}}$ decreased during systole. There was no significant change in the systolic dynamics of $\mathrm{K}_{\mathrm{SL}}$ with contractility at ED, MS, or ES. Unlike any afterload condition, low-dose epinephrine produced an augmentation in $\mathrm{K}_{\mathrm{IC}}$ as systole progressed. This phenomenon was also present at higher doses but did not progress in a dose-dependent fashion. *Significant difference between ED and MS within each contractility condition. $†$ Significant difference between ED and ES within each contractility condition. $¥$ Significant difference between MS and ES within each contractility condition.

\section{Leaflet Curvature}

Intercommisural curvature $\left(\mathrm{K}_{\mathrm{IC}}\right)$ and septolateral curvature $\left(\mathrm{K}_{\mathrm{SL}}\right)$ are summarized at $\mathrm{ED}$, MS, and ES for each condition in Tables 3 and 4, and depicted continuously during the cardiac cycle for a composite sheep in Figures 2 and 3. All curvatures are presented as concave toward the ventricle. Multivariate analysis of variance identified direction on the leaflet and time during systole as significant factors influencing degree of curvature. Of all the time points, $\mathrm{K}_{\mathrm{SL}}$ was significantly larger than $\mathrm{K}_{\mathrm{IC}}$ for all afterload and contractility conditions. Subsequent $t$ tests with Bonferroni correction demonstrated significant differences between $\mathrm{K}_{\mathrm{SL}}$ and $\mathrm{K}_{\mathrm{IC}}$ at $\mathrm{ED}, \mathrm{MS}$, and $\mathrm{ES}$ in all conditions $(P<.05)$.

With regard to time during systole, $\mathrm{K}_{\mathrm{SL}}$ varies more consistently and to a greater degree over the cardiac cycle than $\mathrm{K}_{\mathrm{IC}}$. For all hemodynamic conditions $\mathrm{K}_{\mathrm{SL}}$ was significantly larger at ED than at other times during systole (leaflet flattening during systole).

Increases in afterload had no significant effect on curvature in either direction. Epinephrine infusion had no effect on $\mathrm{K}_{\mathrm{SL}}$. Low-dose epinephrine infusion produced a systolic augmentation of $\mathrm{K}_{\mathrm{IC}}$, but increasing doses had no significant additional effect.

Echocardiography documented normal leaflet motion and valve competence at all hemodynamic conditions.

\section{Comment}

This report represents the first detailed quantitative analysis of leaflet curvature throughout systole. The data demonstrate that curvature varies significantly with direction on the leaflet surface (ie, $\mathrm{K}_{\mathrm{SL}}$ always greater than $\mathrm{K}_{\mathrm{IC}}$ ) at all time points during systole at all hemodynamic conditions. Curvature in the mid-septolateral direction is approximately double the curvature in the intercommisural direction. Because $\mathrm{K}_{\mathrm{SL}}$ is likely influenced by the length of the anterior leaflet and changes in $\mathrm{K}_{\mathrm{IC}}$ are more closely related to annular saddle shape, this finding is consistent with our previous theoretic work that demonstrated leaflet billowing
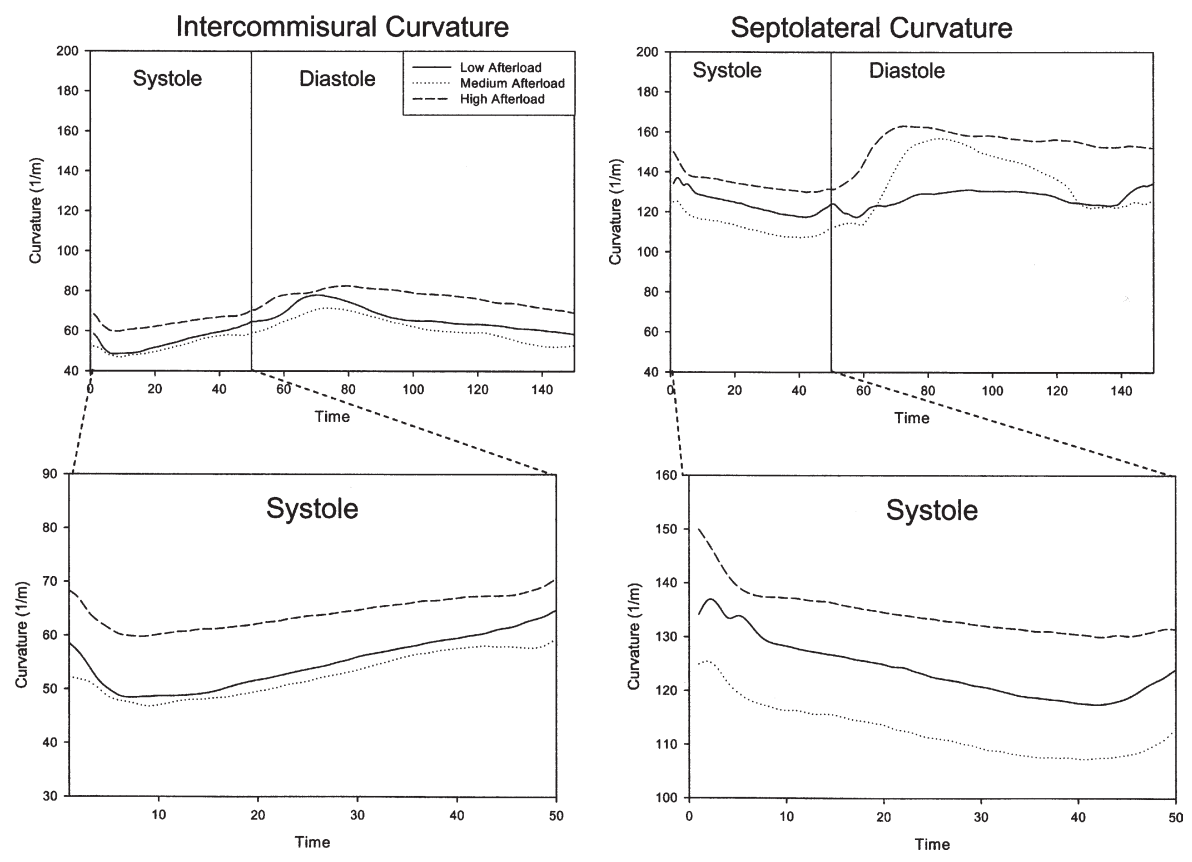

Figure 2. Effect of varying afterload on dynamic leaflet curvature. Intercommisural and septolateral curvature throughout the cardiac cycle for a composite sheep. Data from all sheep were normalized in time and averaged to produce the composite animal. Complete cardiac cycle (upper frames). Changes during systole (lower frames). Intercommisural curvature remains constant throughout systole and is unaffected by increases in afterload. Septolateral curvature decreases during systole; these dynamic changes were not significantly influenced by increasing afterload. 

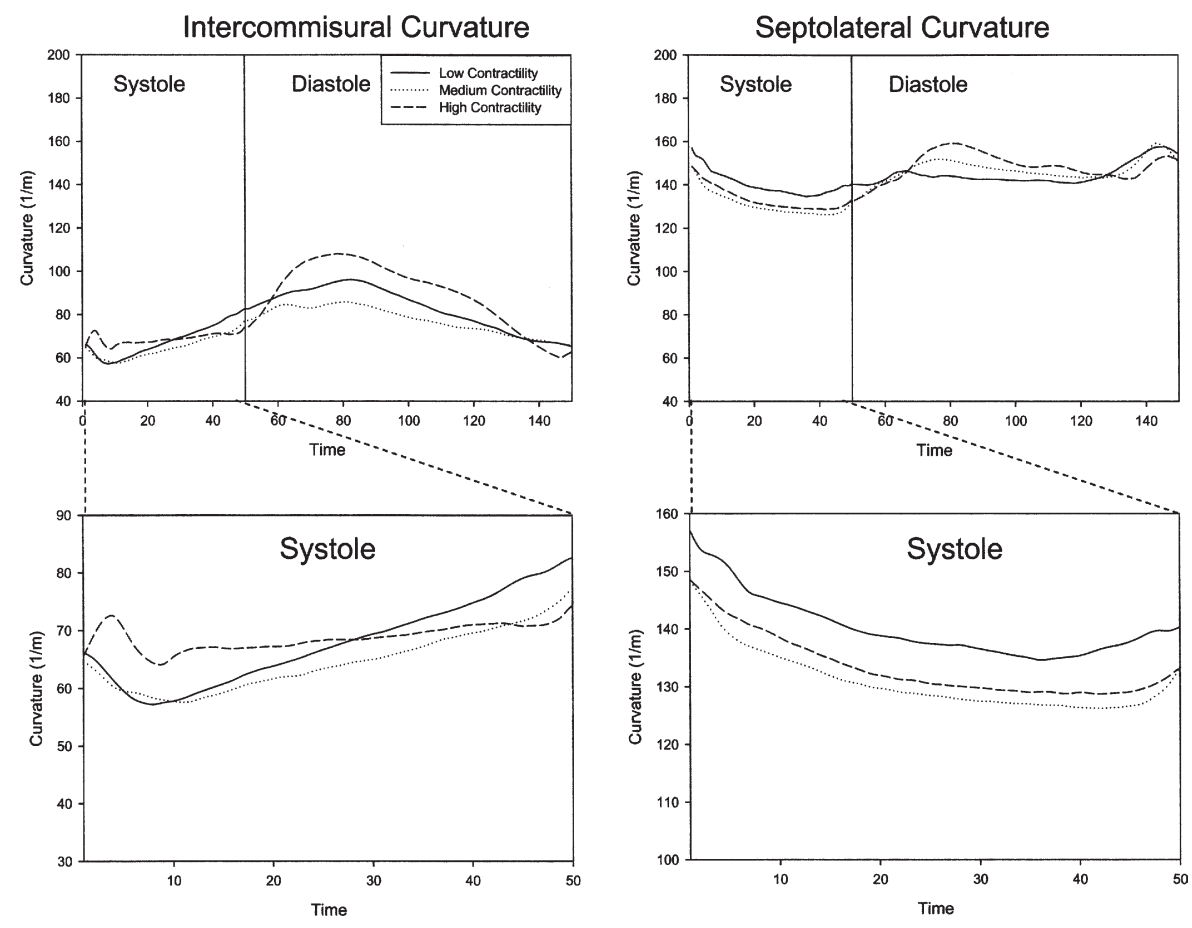

Figure 3. Effect of varying contractility on dynamic leaflet curvature. Intercommisural and septolateral curvature throughout the cardiac cycle for a composite sheep. Data from all sheep were normalized in time and averaged to produce the composite animal. Complete cardiac cycle (upper frames). Changes during systole (lower frames). Low-dose epinephrine infusion causes an augmentation in intercommisural curvature during systole that was not present with phenylephrine hydrochloride (Neo-Synephrine; Bayer, Pittsburgh, $\mathrm{Pa}$ ) infusions. Septolateral curvature decreased during systole; these dynamic changes were not affected by increased contractility.

to be the major contributor to leaflet curvature with annular saddle shape playing a lesser, although important, role. ${ }^{8}$

Leaflet curvature decreases in the septolateral direction during early systole (ED to MS). A potential explanation for this flattening is that as loading proceeds during early systole, leaflet tissue is unfurled causing the leaflet to become more taut as left ventricular pressure increases. The flattening may also be influenced by the pull of the contracting papillary muscles (by the first and second order chords) on the leaflet edge and belly.

Intercommisural curvature varies over systole only when epinephrine is given. This finding may result from a combination of increased pulling by second-order chordae (from increased papillary muscle contraction) ${ }^{12}$ and the augmentation of the mitral annular saddle shape seen when ventricular contractility is increased. ${ }^{11,13}$

Despite the subtle effect of epinephrine, the majority of the data indicate that leaflet curvature remains constant over a wide range of physiologic loading and contractile conditions. In other experiments, we showed that both annular shape and size vary significantly with similar variation in contractility and afterload. ${ }^{13,14}$ In light of this previous work it can be hypothesized that changes in annular size and shape vary to furl and unfurl leaflet tissue (in sheep, the leaflet area is approximately 1.5 times that of the annular area $)^{10}$ to maintain a constant leaflet curvature over a wide range of conditions.

This work represents another indication of just how subtle the functioning of the competent mitral valve really is. Although not directly measured during this study, annular size and shape likely vary synergistically to optimally distribute excess leaflet tissue to preserve curvature, minimize leaflet stress, and preserve valve competence. Support for this concept of dynamic interplay between annular and leaflet geometry can also be seen in work done by our group and the Stanford group regarding the pathogenesis of ischemic mitral regurgitation. It has been shown that valve incompetence in this disease process is associated with annular dilatation, ${ }^{14,15}$ diminution of the saddle shape, ${ }^{15,16}$ and leaflet flattening. ${ }^{17}$

Along with being technically demanding from both a surgical and data analysis standpoint, the marker imaging techniques used by our group and the Stanford group can be potentially criticized for altering the phenomenon they are trying to measure by distorting leaflet shape and hindering leaflet motion. In practice, such interference is relatively minimal. All animals in this study had normal leaflet motion and function documented by echocardiography. Figure 4 demonstrates echocardiographic images from a representative sheep during systole and diastole. Furthermore, the techniques used are the only quantitative imaging modalities with the spatial and temporal resolution necessary to answer questions regarding the behavior of fast-moving cardiac structures. ${ }^{10}$ The data produced by these techniques are progressively being incorporated into mathematic models of the mitral valve.

We describe the synchronous changes in septolateral and intercommisural anterior leaflet curvature for the first time, 

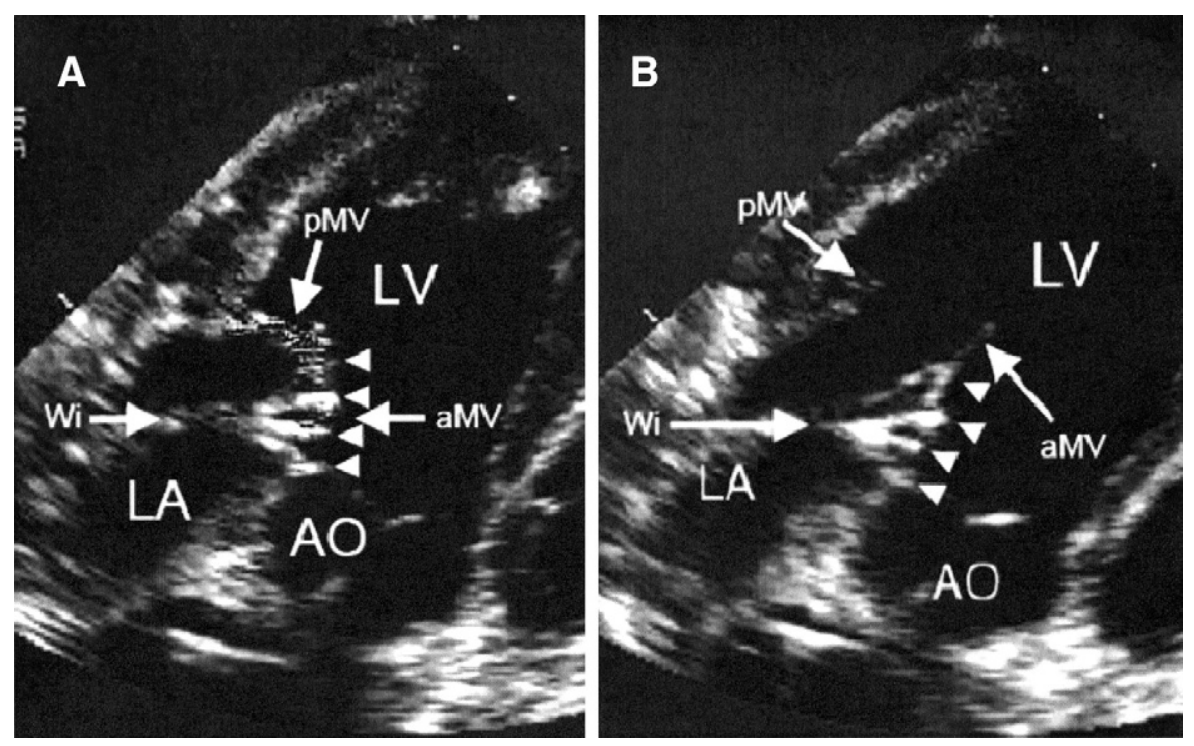

Figure 4. Echocardiographic images of the mitral valve during systole (A) and diastole $(B)$ in a representative instrumented sheep. Note that the valve opens and closes completely after being instrumented with $\mathbf{5}$ sonomicrometry transducers. $p M V$, Posterior leaflet of the mitral valve; $a M V$, anterior leaflet of the mitral valve; $A O$, aorta; $L A$, left atrium; $L V$, left ventricle; $W i$, sonomicrometry wires. Sonomicrometry crystals (arrowheads).

but the current study demonstrated less spatial resolution in the septolateral direction than in previous studies. ${ }^{12,18}$ With 3 transducers sutured in the septolateral direction, only 1 curve could be calculated from the marker triplet. As a result, the septolateral transducer array used characterizes only the concave aspect of the anterior mitral leaflet curvature and corresponds to the distal leaflet marker array from previous reports. ${ }^{12,18}$ The convex curvature near the annular region of the anterior leaflet was not assessed. ${ }^{17}$

Despite these shortcomings, these models, in conjunction with parallel studies using real-time 3-dimensional echocardiography, will ultimately provide a quantitative "view" of the mitral valve that will allow surgeons and engineers to develop devices and techniques that improve repair longevity.

\section{References}

1. Accola KD, Scott ML, Thompson PA, Palmer GJ 3rd, Sand ME, Ebra G. Midterm outcomes using the physio ring in mitral valve reconstruction: experience in 492 patients. Ann Thorac Surg. 2005;79:1276-83.

2. Fasol R, Meinhard J, Deutsch M, Binder T. Mitral valve repair with the Colvin-Galloway Future Band. Ann Thorac Surg. 2004;77:1985-8.

3. Flameng W, Herijgers P, Bogaerts K. Recurrence of mitral valve regurgitation after mitral valve repair in degenerative valve disease. Circulation. 2003;107:1609-13.

4. Gillinov AM, Cosgrove DM 3rd, Shiota T, Qin J, Tsujino H, Stewart WJ, et al. Cosgrove-Edwards Annuloplasty System: midterm results. Ann Thorac Surg. 2000;69:717-21.

5. Mazumadar K, Hearn TC. Mathematical analysis of mitral valve leaflets. J Biomech. 1978;11:291-6.

6. Arts T, Meerbaum S, Reneman R, Corday E. Stresses in the closed mitral valve: a model study. J Biomech. 1983;16:539-47.
7. Miller GE, Marcotte H. Computer simulation of human mitral valve mechanics and motion. Comput Biol Med. 1987;17:305-19.

8. Salgo IS, Gorman JH III, Gorman RC, Jackson BM, Bowen FW, Plappert $\mathrm{T}$, et al. Effect of annular shape on leaflet curvature in reducing mitral leaflet stress. Circulation. 2002;106:711-17.

9. Kelley ST, Malekan R, Gorman JH 3rd, Jackson BM, Gorman RC, Suzuki Y, et al. Restraining infarct expansion preserves left ventricular geometry and function after acute anteroapical infarction. Circulation. 1998;98:II62-5

10. Gorman JH 3rd, Gupta KB, Streicher JT, Gorman RC, Jackson BM, Ratcliffe MB, et al. Dynamic three-dimensional imaging of the mitral valve and left ventricle by rapid sonomicrometry array localization. J Thorac Cardiovasc Surg. 1996;112:712-26.

11. Parish LM, Jackson BM, Enomoto Y, Gorman RC, Gorman JH 3rd. The dynamic anterior mitral annulus. Ann Thorac Surg. 2004;78: 1248-55.

12. Rodriguez F, Langer F, Harrington KB, Tibayan FA, Zasio MK, Liang $\mathrm{D}$, et al. Effect of cutting second-order chordae on in-vivo anterior mitral leaflet compound curvature. J Heart Valve Dis. 2005;14:592601.

13. Gorman JH 3rd, Jackson BM, Moainie SL, Enomoto Y, Gorman RC. Influence of inotropy and chronotropy on the mitral valve sphincter mechanism. Ann Thorac Surg. 2004;77:852-7.

14. Gorman JH 3rd, Gorman RC, Jackson BM, Enomoto Y, St JohnSutton MG, Edmunds LH Jr. Annuloplasty ring selection for chronic ischemic mitral regurgitation: lessons from the ovine model. Ann Thorac Surg. 2003;76:1556-63.

15. Tibayan FA, Rodriguez F, Langer F, Zasio MK, Bailey L, Liang D, et al. Annular remodeling in chronic ischemic mitral regurgitation: ring selection implications. Ann Thorac Surg. 2003;76:1549-54.

16. Gorman JH 3rd, Jackson BM, Enomoto Y, Gorman RC. The effect of regional ischemia on mitral valve annular saddle shape. Ann Thorac Surg. 2004;77:544-8.

17. Tibayan FA, Rodriguez F, Langer F, Zasio MK, Bailey L, Liang D, et al. Increases in mitral leaflet radii of curvature with chronic ischemic mitral regurgitation. J Heart Valve Dis. 2004;13:772-8.

18. Timek TA, Lai DT, Dagum PT, Liang D, Daughters GT, Ingels NB Jr, et al. Mitral leaflet remodeling in dilated cardiomyopathy. Circulation. 2006;114:I518-23. 